\title{
Apostillas de Ricardo Palma a las acuarelas de Pancho Fierro
}

Por Wilfredo Kapsoli Escudero 
Doctor en Letras (Historia) por la Universidad Nacional Mayor de San Marcos. Posee estudios de posgrado en la Escuela Práctica de Altos Estudios de París. Ha sido becado por la Comunidad Científica Japonesa a la Universidad Nanzan de Nagoya. 


\section{Introducción}

Los libros que se leían antiguamente siempre contaban con las huellas del lector. Pues, casi siempre, anotaban sus impresiones y comentarios en los márgenes de la obra. Esta costumbre recibía el nombre de apostilla que, según el Diccionario de la Real Academia de la Lengua Española, significa: "acotación que comenta, interpreta o completa un texto".

Raúl Porras Barrenechea escribió un bello ensayo sobre La Historia de las Indias de Francisco de Gómara, apostillado por el Inca Garcilaso de la Vega con numerosos autógrafos, correcciones y adiciones. De suerte que esta crónica "conserva la huella viviente de uno de los más grandes forjadores espirituales del Perú". Revela también su método de trabajo: "Anotaba al margen sus recuerdos más premiosos, que le servían como puntales para futuras disquisiciones". O, en ocasiones, el Inca se solazaba con frases para avivar la curiosidad de los bibliófilos, como nos lo hace conocer Porras:

“... acaso la nota manuscrita más humorística del libro se refiere a un episodio de la vida del conquistador y vecino del Cusco Francisco de Villacastín, que perdió dos dientes a consecuencia de la pedrada de una mona, nota que, para mayor realce, está firmada y rubricada por Garcilaso"; quien, a su vez afirmó: "Yo vi sus dientes quebrados, eran 
los delanteros altos y era de pública voz y fama en el Perú habérselos quebrado la mona".

Por nuestra parte, el homenaje a Emilio Choy (como introducción al 3er. tomo de sus obras completas), lo preparamos en base a las apostillas que había dejado al leer los libros de Denix Cuché, Poder Blanco y Resistencia Negra y de Germán Carrera Damas sobre Tomas Boves Prócer de la Independencia Venezolana.

\section{Acuarelas de Pancho Fierro}

Una serie de imágenes, pinturas y murales nos permiten apreciar con deleite la vida cotidiana, las fiestas y cultos religiosos de fines de la Colonia y principios de la República.

Gustavo León y León Durán ha publicado el libro titulado Apuntes histórico genealógicos de Pancho Fierro al cual remitimos al lector interesado en la biografía prolijamente documentada del autor.

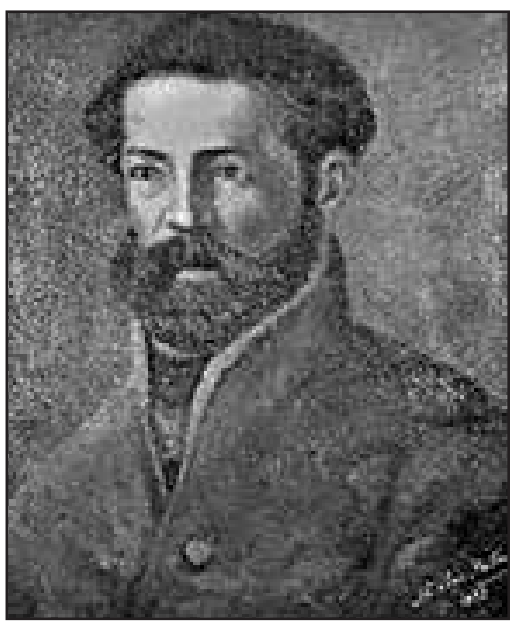

Retrato de Pancho Fierro 
Pancho Fierro tuvo como antecesores a Felipe Guamán Poma de Ayala y a Martínez Compañón, quienes en su momento documentaron gráficamente distintos aspectos del mundo de los incas y de la sociedad colonial (Cf. la bibliografía de este texto). Pero él tuvo la particularidad de añadir un carácter festivo y caricaturesco a sus representaciones artísticas.

Angélica Palma en su ensayo Pancho Fierro Acuarelista Limeño, considera que en su obra aparecen los ecos de la Lima del ochocientos, los sentimientos y costumbres ya lejanos, que solo existen para la ciudad actual en libros viejos y láminas antiguas:

"Nacido en los albores del siglo diecinueve, como queda dicho, pasó Pancho Fierro los veinte primeros años de su existencia en la condición de súbdito de la Monarquía y en la de testigo, tal vez actor, de la lucha emancipadora; sin embargo, solo pueden considerarse alusivas a esta época, entre las láminas del acuarelista, las rotuladas Un sitiador del Callao, Un oficial del ejército argentino-chileno, "Fui del ejército libertador y El Sargento Zapata", retrato de las dos últimas de un negro guerrero que, recordando orgulloso en la ancianidad las pretéritas hazañas, solemnizaba las fiestas del aniversario patrio vistiéndose el uniforme militar y prendiendo en él las condecoraciones ganadas a sangre y fuego".

Francisco Stastny ha preparado un estudio erudito sobre el significado y valor social de su obra. Él considera que no es extraño que doscientos años más tarde Pancho Fierro sea el primer pintor que se enfrentó a la realidad cotidiana de la sociedad peruana mostrando los barrios de la ciudad, con el humor sutil que lo caracterizó, desde el discurso acerca de la justicia frustrada que obsesionó a sus antepasados indígenas, criollos y españoles. Luego, añade: 
"La multitud de acuarelas producidas por Pancho Fierro a lo largo de su vida se calcula en varios miles, cuyos prototipos fueron repetidos en muchos ejemplares para atender la demanda. A edad temprana el pintor ya había identificado el interés de los viajeros que llegaban a la ciudad por conocer las originalidades de la vida limeña y particularmente los aspectos más arcaicos que reflejaban las costumbres de la época colonial".

A parte de esta referencia general, Stastny precisa que los ámbitos que exploró fueron:

a. Los mercados callejeros y los vendedores ambulantes que recorrían la ciudad.

b. Los negocios de comida y de chicha.

c. Las vestimentas y costumbres originales de las tapadas.

d. Todo lo referente a los festejos y a las diversiones públicas (danza de la diablada, cuadrilla de indios, corridas de toros, peleas de gallo).

e. Las fiestas y las danzas domésticas.

f. La vida de los soldados y sus rabonas.

g. Las actividades de los religiosos en la ciudad aunque no en sus recintos eclesiásticos.

h. Algunas escenas de la vida de salón.

i. Los indios y el culto a los muertos.

j. Los barrios populares y el trabajo de las lavanderas al lado de las acequias. 
k. Los personajes notables y los locos mansos de la calle.

Pero, lo más significativo de su valoración se encuentra en sus reflexiones sobre los murales que pintó Pancho Fierro y que representan las escenas de "De un mundo al revés" de las cuales se citan cuatro ejemplares distribuidos en diversos barrios de Lima. Una estuvo en una casa en la Alameda de Acho, frente al río; otra en una pulpería en la esquina de las calles de Santa Ana con Sacramento, destruida lamentablemente por un incendio en 1888.

En la calle Animita figuraba otra variante pintada tardíamente en 1877, solo dos años antes de fallecer el pintor. Finalmente, se menciona que hubo un mural parecido en la Alameda al inicio del camino al Callao. (Tanto ésa como la de Acho fueron descritas por Ricardo Palma como obras coloniales que existieron alrededor de 1830, dato difícil de asumir). En aquellas composiciones se veían las más absurdas alteraciones del orden normal de las cosas. Parejas de hermosos caballos se paseaban sentados en carruajes, jalados por seres humanos. Un pequeño pez echa el anzuelo al agua y extrae a un pescador atrapado. Los alumnos castigan a su profesor. El usurero cumple actos de caridad. El toro clava con elegancia banderillas al lidiador. Y así sucesivamente se recorren las más variadas situaciones de la vida social.

Como idea iconográfica y reflejo de viejos mitos, $\boldsymbol{E l}$ mundo al revés es, sin lugar a dudas, uno de los más fascinantes temas tratados por Pancho Fierro, y que correspondió muy bien a la época revolucionaria de su adolescencia. La inversión del orden social es una idea que ha rondado el pensamiento y las artes de las civilizaciones más variadas. Se la encuentra en el arte prehispánico de América desde tiempos remotos, y en Europa. A veces actuó como un sistema ritual controlador de la transformación, y otras, como el reflejo de desatadas explosiones revolucionarias". 
De este modo, Pancho Fierro habría testimoniado plásticamente el Pachacutic (mundo al revés andino) imaginado como el retorno feliz a la sociedad Inca.

2. Apostillas de Ricardo Palma a las acuarelas de Pancho Fierro.

El año 2007, la Municipalidad de Lima publicó la obra Las acuarelas de Pancho Fierro y sus Seguidores donde se insertó como addenda Los Manuscritos de Ricardo Palma. Transcripción de Comentarios. En esta sección ubican en el primer espacio la acuarela, en el siguiente los manuscritos y, al final, la trascripción digitalizada de dichos textos. La colección de acuarelas de Ricardo Palma bordean las 250 unidades, en las cuales nuestro tradicionista realizó una serie de apostillas, algunas más extensas que otras. Sin dejar de lado, en algunas de ellas, solo la indicación del oficio o labor que se presenta.

Es interesante anotar que Ricardo Palma consideró a Pancho Fierro como el "Goya limeño".

Igualmente, nueve años después del deceso de Pancho Fierro, el mismo Ricardo Palma se vuelve a referir al pintor al comentar la ilustración del autor a El Paseo de Alcaldes donde muestra el fastuoso cortejo de esta ceremonia oficial, cuya copia se inserta en el Semanario "El Perú Ilustrado", y señala textualmente que "Debemos al inimitable lápiz de Pancho Fierro, quien presenció los Paseos del Estandarte desde 1815 hasta 1820".

Oswaldo Holguín, por su parte, tiene un ensayo sobre Ricardo Palma y la cultura negra donde nos hace conocer que nuestro tradicionista tuvo en sus ancestros directos sangre negra. Así ,su madre fue una cuarterona y, por lo mismo, su atención e identificación con los esclavos y sus descendientes fue notoria tanto en sus Tradiciones, en sus poesías y en 
las apostillas a las acuarelas que en este caso pertenecían a Pancho Fierro, igualmente de ascendencia morena.

Nosotros hemos seleccionadolas acuarelas más representativas que a, nuestro parecer, simbolizan emblemáticamente personajes y escenas de la época colonial y republicana.

A continuación presentamos dicha elección con los comentarios e impresiones de Ricardo Palma y algunas reflexiones nuestras que consideramos oportunas.
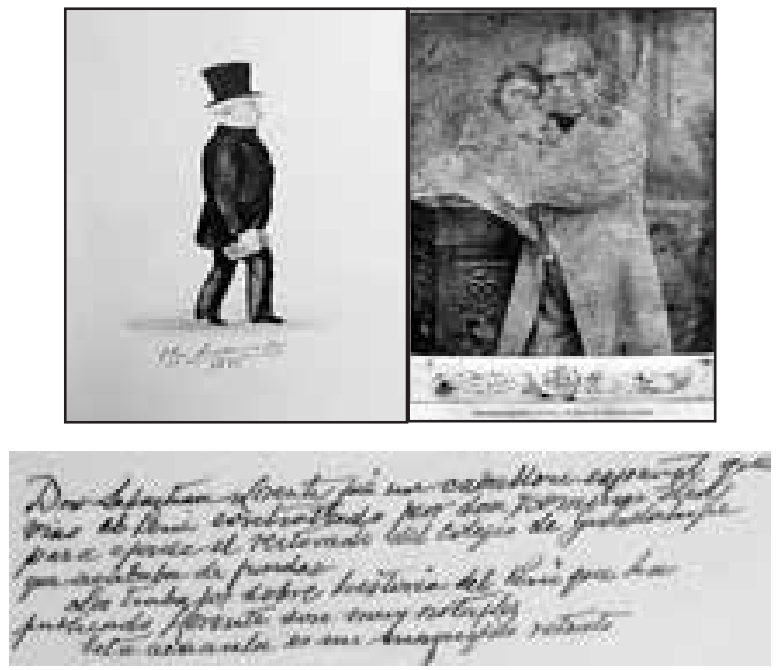

Un historiador

(Don Sebastián Lorente 1870)

"Don Sebastián Lorente fue un caballero español que vino al Perú contratado por don Domingo Elías para ejercer el rectorado del colegio de Guadalupe que acababa de fundar. Los trabajos sobre Historia del Perú que ha publicado Lorente son notables. 
Sobre su producción intelectual y labor pedagógica confróntese los textos de Pedro Zulen en El Boletín Bibliográfico de la Universidad de San Marcos de 1923 y Las Actas del Conversatorio sobre Sebastián Lorente (2010).

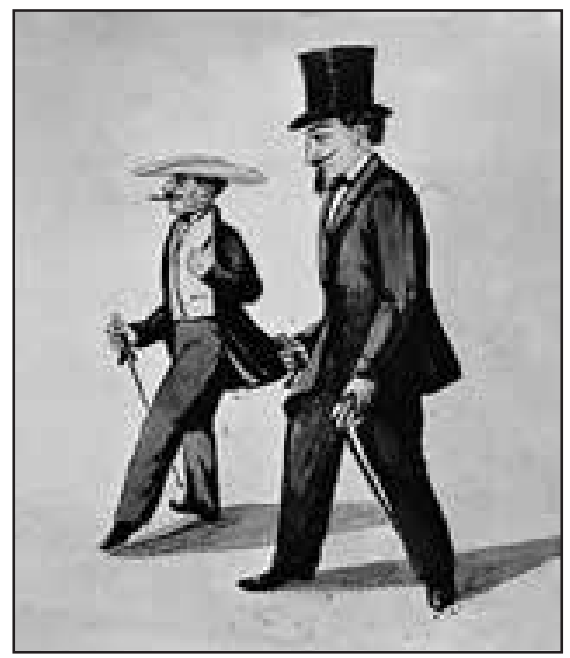

En relación a esta imagen, Manuel Cisneros nos dice: "En la colección García Calderón, hoy en nuestro poder, existe una acuarela en la que aparece el Mariscal Castilla vestido de civil, caminando acompañado de Morales, pero ésta, como otras en que figura el Mariscal, no tiene mayor intención como no sea la de reflejar la simpatía que pudo tener nuestro artista por don Ramón". Luis Cuneo en un artículo curioso sobre la presencia del mariscal como devoto de la virgen del Rosario de Tacna, comenta que: "la figura de Castilla era poco gallarda". Y señala que el viajero francés Charles Wiener lo describe así: "Enjuto y desgarbado, no se podía negar que por sus venas corrían algunas gotas de sangre negra y de sangre india, como de sobra lo indica su figura original. Ligeramente bronceado y desprovisto de barba, pues apenas poseías algunos ralos pelos sobre el labio superior". 


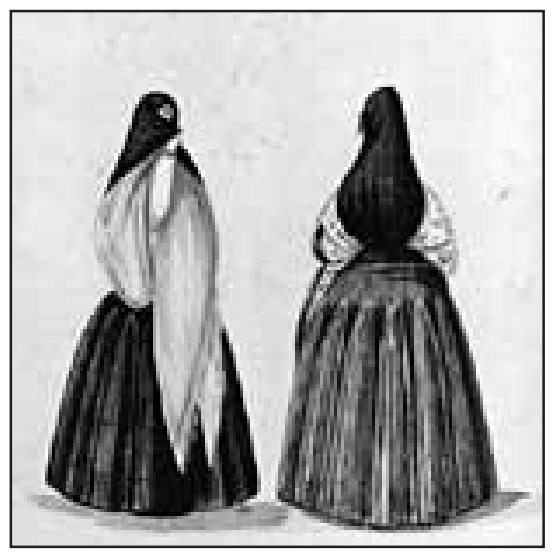

La primera tapada lleva la saya llamada orbegosina que empezó a usarse en 1834, siendo Presidente del Perú el General Orbegoso. También se la llamó saya salaverrina. La otra tapada lleva la saya verde o gamarrina que empezó a usarse desde 1829 por las limeñas partidarias del General Gamarra. La saya salaverrina (orbegosina) prevaleció hasta después de 1855 en que las modas francesas proscribieron la saya y manto, proscripción que ni excomuniones de un Concilio limense ni ordenanzas de varios virreyes habían logrado hacer prácticas.

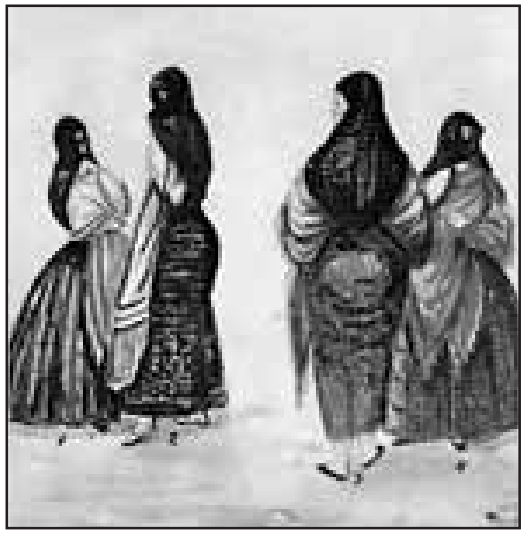


La primera tapada luce la saya llamada de tiritas, disfraz que usaban las limeñas para ir de paseo a la Alameda en el día de la Porciúncula y en otras dos o tres festividades. El lujo era llevar saya muy rotosa y remendada, haciendo contraste con la riqueza del chal o pañolón, pulseras y demás adornos.

José Sabogal considera a la "tapada" la figura predilecta de Pancho Fierro; no dejó de llevar a su cuaderno ningún gesto, visto y sentido en plenitud, de esta bella figura limeña. Por las "tapadas" de este pintor criollo sabemos del encanto que emanaba de su gracia, brío, "lisura" y de los espléndidos ejemplares de mujer de aquellos tiempos románticos.
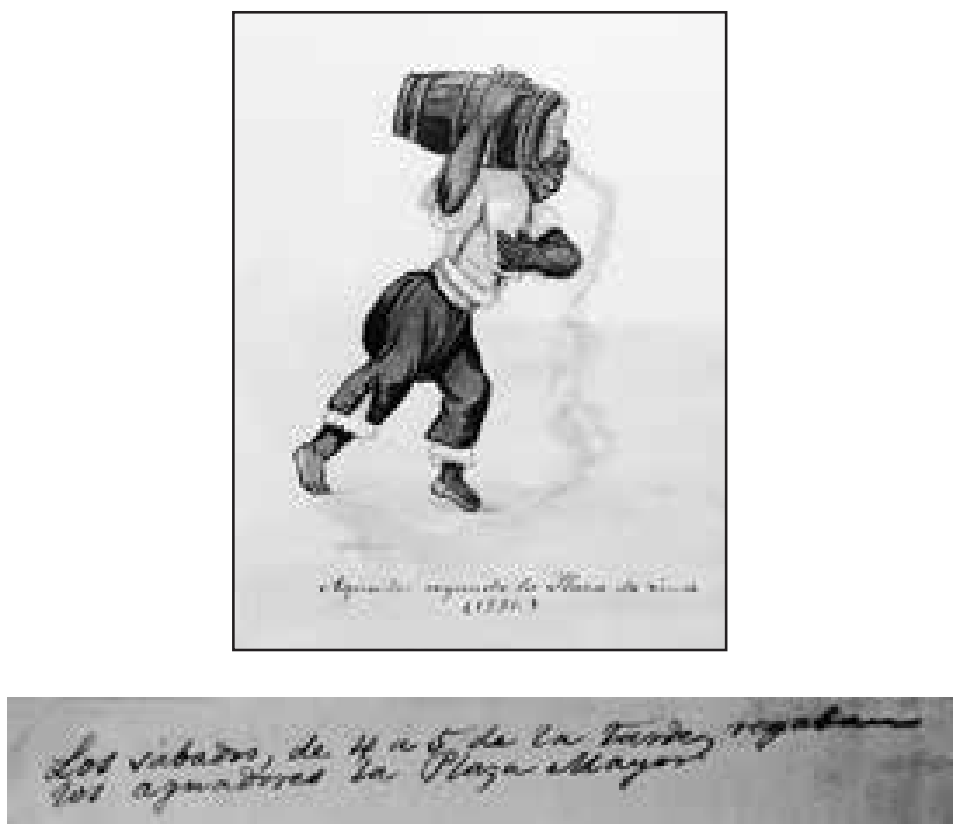

"Los sábados de 4 a 5 de la tarde regaban los aguadores la Plaza Mayor". Sobre el oficio y todo el entorno vinculado a su práctica Ricardo Palma los describió en la siguiente tradición: 


\section{Los aguadores de Lima}

Los proveedores de agua a domicilio, o aguateros, como con mejor índole filológica dicen los argentinos, constituyeron en Lima un gremio sujeto a pragmática o reglamentación, gremio que, a Dios gracias, ha muerto desde casi medio siglo, y sin esperanza de resurrección, pues como dice un poeta:

Aquel que dijo a Lázaro: "iLevanta!", no ha vuelto en los sepulcros a llamar.

Cuando fundó Pizarro la ciudad, tenían los vecinos que ocupar un doméstico para que, en grandes cántaros de barro, trajese del río al hogar el refrigerante e imprescindible líquido.

Tan luego como la trata de negros se generalizó, las personas acomodadas quisieron consumir mejor agua que la del cauce del río, y mandaban un esclavo, caballero en un asno, que sustentaba un par de pipas, a proveerse de agua clarísima de la Piedra Lisa y de otras vertientes vecinas a la ciudad.

Después que en 1650 se erigió, con gasto de ochenta mil pesos, la pila monumental, que aún perdura en la plaza Mayor, se asociaron quince o veinte negros libertos organizando un gremio para proveer de agua a los vecinos, asignando el precio de medio real de plata por cada viaje. Un viaje de agua constaba de dos pipas.

Desde sus primeros tiempos se singularizaron los aguadores por la desvergüenza de su vocabulario, tanto que era como refrán para las buenas madres limeñas el reprender a sus hijos diciendo: -Callen, niños, que por las lisuras que dicen me parecen aguadores.

Los del ambulante gremio se anunciaban con el tintineo de una campanilla que sonaba a cada paso del asno, y conforme 
a su pragmática o reglamento estaban obligados a consagrar quincenalmente una tarde a la matanza de perros callejeros que no ostentaran un collarín, obtenido por sus dueños de la autoridad de policía, previo pago de dos pesos. Barato era el seguro de vida, siendo el mes de diciembre el designado para la renovación de la póliza, digo, argolla.

La matanza la ejecutaban los aguadores armados de gruesa tranca con contera de plomo, y en esa tarde era horrible y repugnante el espectáculo que ofrecían las calles de Lima. Fue después de la batalla de la Palma, esto es, en 1856 ó 57, cuando el bocadillo de carne envenenada substituyó al feroz garrote, sistema que no admitía privilegiadas excepciones caninas. Igualdad ante la ley de muerte: tan perro era el chusco como el mimado falderito.

Quien deseaba salvar a su doméstico cancerbero tenía que vivir averiguando por el aguador de la casa cuándo era el día del bocadillo, a fin de mantener encerrado al ladrador. Cuando cesó de funcionar el gremio, quedaron los perros en Lima como moros sin señor y libres de todo susto.

El establecimiento de la perrera municipal, reforma que aplaudo, es, como quien dice, de ayer por la mañana.

Los aguadores festejaban anualmente, en la iglesia de San Francisco, a San Benito, patrón del gremio, y era para ellos ese día de ancho jolgorio.

Al incorporarse un aguador en el gremio, entregaba cuatro pesos al alcalde para fondos de la asociación, al incremento de los cuales contribuía semanalmente con la cuota de un real de plata.

También estaban obligados a regar cada sábado, de cuatro a cinco de la tarde, la Plaza Mayor y las plazuelas de San Francisco, Santo Domingo, la Merced y San Agustín. 
Cuando desapareció el gobierno monárquico y vino la república «con sus farolerías de igualdad democrática, el gremio de aguadores se convirtió en potencia política para los actos eleccionarios. El alcalde se transformó en personaje mimado por los caudillos. El que contaba con el gremio tenía asegurado triunfo en las elecciones parroquiales de la capital de la república. La disciplina era una maravilla, pues nadie osaba hacer la más ligera observación a un mandato del alcalde. Al ingresar en el gremio, todos los asociados habían prestado juramento de ciega obediencia. Eso sí que era autocracia, y no pampirolada como la del zar de Rusia.

Hubo en Lima, por los años de1850, un caballero acaudalado, al que bautizaremos con el nombre de don José Francisco, pero muy metido siempre en belenes de política, el cual calculó que el hombre que consiguiera adueñarse de los aguadores sería siempre el mimado por los magnates de palacio, lo que se llama una potencia. Nuestro politiquero se convirtió en paño de lágrimas para con los del gremio que en cualquier tribulación doméstica acudían a él, y con frecuencia los salvaba de ir a la cárcel por borrachos y pendencieros. El era obligado padrino de bautizo de los retoños, y por supuesto que siempre tenía compadre alcalde. Tuteaba a todos los aguadores, y hasta les daba monises para que a su salud bebiesen copas en la pulpería.

En una ocasión viéronse varios aguadores complicados en un juicio por pecado de hurto. Don José Francisco se puso en movimiento, y después de recia fatiga consiguió que el juez sobreseyera en la causa, dejando a los acusados en libertad para repetir la hazaña. El gremio, agradecido, sin que discrepara voto, nombró a don José Francisco aguador honorario, distinción que a nadie se había hasta entonces acordado.

Los sábados, a las tres de la tarde, se congregaban los aguadores alrededor de la gran pila de la Plaza. A nuestro politiquero se le 
veía paseando delante de la arquería del Portal de Botoneros, y cuando al pasar lista gritaba el alcalde: José Francisco, aguador honorario-, nunca dejó de oírse la voz que contestaba: iPresente, señor alcalde!; y cumplido el deber disciplinario se iba, paso entre paso, a su domicilio.

Después de la lista, discutían sus asuntillos los asociados, y terminada la junta empezaba el regadío de la Plaza.

La acción de los aguadores en la vida política era la siguiente; desde la víspera del día designado por la ley para la constitución de las mesas distritales, que debían recibir el sufragio de los ciudadanos, los aguadores se congregaban en algún casaron viejo, dejando a los partidos contendientes en libertad para la lucha. Los aguadores, en su encierro, eran sólo un cuerpo de expectativa o de reserva, que había pasado las horas consumiendo aguardiente y butifarras, hasta que les llegaba la noticia de que el partido popular o de oposición al gobierno había triunfado o estaba en vía de adueñarse de la mesa de la parroquia de San Marcelo, por ejemplo. Ese era el instante en que aparecía don José Francisco revólver en mano, y gritando: -iA tomar la mesa de San Marcelo! iA San Marcelo, muchachos! iViva el gobierno!-.

Repetía la excitación el alcalde, con un énfasis que se prestaba a esta disparatada traducción criolla: - Muchachos, aquí no hay más Dios que Mahoma y don José Francisco, que es su profeta.

Y garrote en mano, daga o puñal al cinto, en medio de espantosa gritería y a carrera abierta, se lanzaban los doscientos negros aguadores sobre los ocupantes de la plazuela, que tras de ligerísima resistencia y de un par de cabezas rotas, ponían pies en polvorosa. iVictoria por los aguadores... Y por el gobierno! 
A Dios gracias, desde ha casi cuarenta linos, en el campo eleccionario de las parroquias no corre ya sangre. Embolismos y trampas pacíficas en las ánforas han reemplazado al democrático garrote de los aguadores, gremio que ya no es más que uno de tantos recuerdos tradicionales.
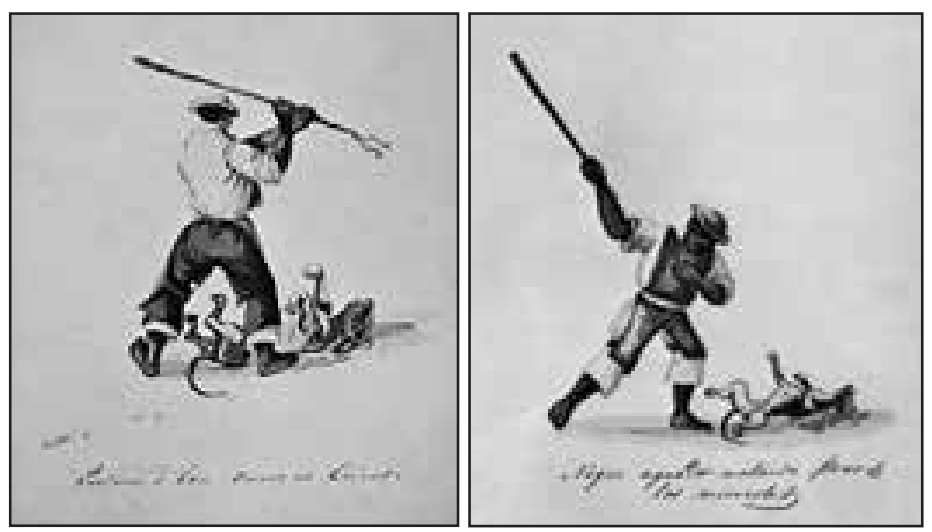

Hasta 1850, la Municipalidad no había adoptado el sistema de emplear bocadillos para destruir perros. Eran los aguadores los que un día en la semana tenían la obligación de matarlos a garrotazos. iRepugnante y bárbaro espectáculo!

Usualmente en los veranos de cada año, existía la costumbre de matar a los perros vagabundos a fin de combatir la enfermedad de la rabia. De ahí surgió el dicho popular: Muerto el perro, muerta la rabia.

También existía el personaje "El perrero de la catedral, que como su título lo indica era este un individuo que ganaba 20 pesos al mes y cuya misión era la de impedir que entrasen perros al templo. El destino parece que fue suprimido en 1850". 

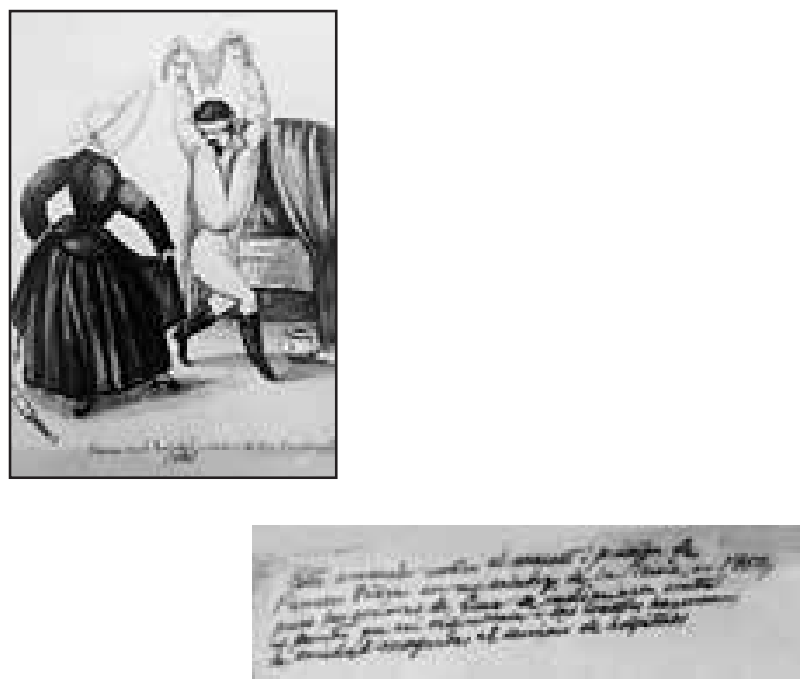

“Esta acuarela motivó el arresto a prisión de Pancho Fierro en un calabozo de la policía en 1850. Pues las señoras de Lima se indignaron contra el pintor que así ridiculizaba a las santas hermanas de caridad consagradas al servicio de hospitales".

Manuel Cisneros, en su obra Pancho Fierro y la Lima del 800, en relación a la acuarela que antecede comenta: "El único incidente conocido que sufrió Pancho Fierro fue una detención policial en 1850, originada por la protesta de un grupo de señoras pacas, contra una acuarela que actualmente se conserva en la Colección Municipal, con la correspondiente anotación de don Ricardo Palma. En ella aparece una hermana de la orden de San Vicente bailando una marinera en el hospital con un militar enfermo, al lado del lecho de éste. En nuestra colección hay una acuarela, también del hospital, de dos hermanas de San Vicente atendiendo a un enfermo, estampa que por no tener la vivacidad de colores común en las obras del artista, permitiría suponer que se trata de uno de sus muy últimos trabajos, sino el último cuando Pancho Fierro ya se encontraba internado en la sala de San José del Hospital 2 de Mayo donde muriera". 

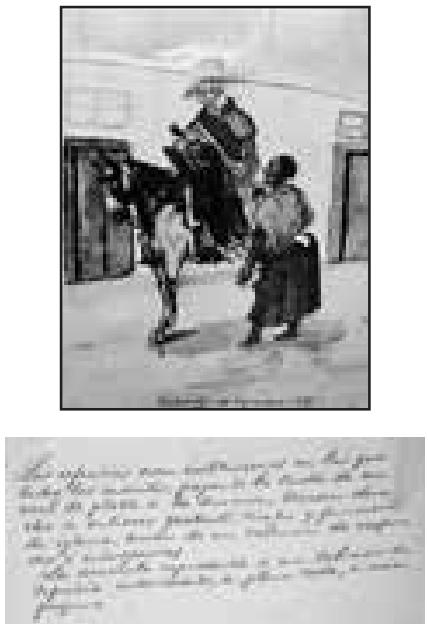

"Las Cofradías eran instituciones en las que todos los inscritos, pagando la cuota de un real de plata a la semana, tenían derecho a entierro gratuito, nicho y función de iglesia, amén de un celemín de responsos $e$ indulgencias. La acuarela representa a su cobrador de cofradía inscribiendo en plena calle a una prójima”.
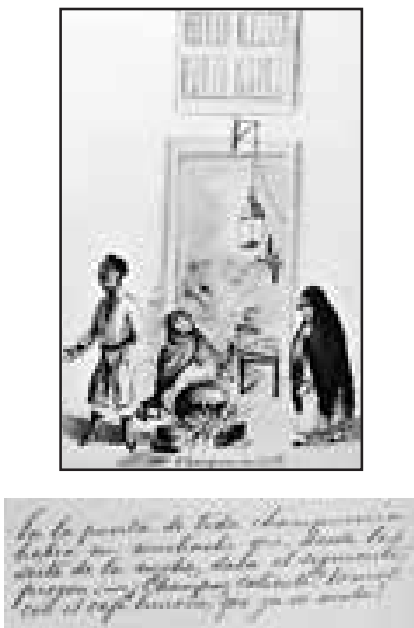
"En la puerta de toda champucería había un muchacho que desde las siete de la noche, daba el siguiente pregón: iChampús caliente!, vamos con el café limeño que ya se acabó".
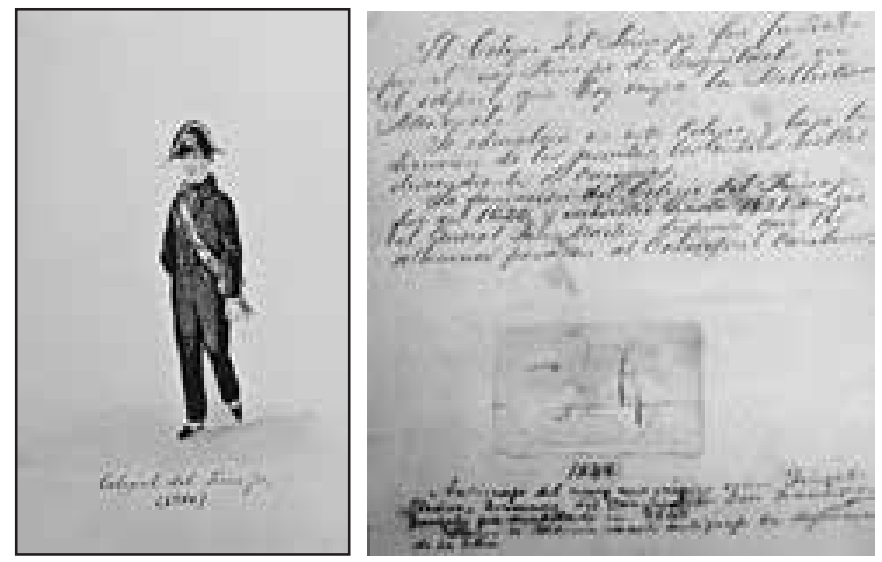

Colegial del Príncipe (1.800)

"El Colegio del Príncipe fue fundado por el virrey Príncipe de Esquilache en el edificio que hoy ocupa la Biblioteca Nacional. Se educaban en este colegio y bajo la dirección de los jesuitas los indios nobles descendientes de caciques. La fundación del Colegio del Príncipe fue en 1620 y subsistió hasta 1821, en que el General San Martín dispuso que los alumnos pasasen al Convictorio carolino".

Autógrafo del muy magnífico señor Gonzalo Pizarro, hermano del Conquistador Don Francisco, Gonzalo fue decapitado en 1548. Llama la atención en este autógrafo la elegancia de la letra. 

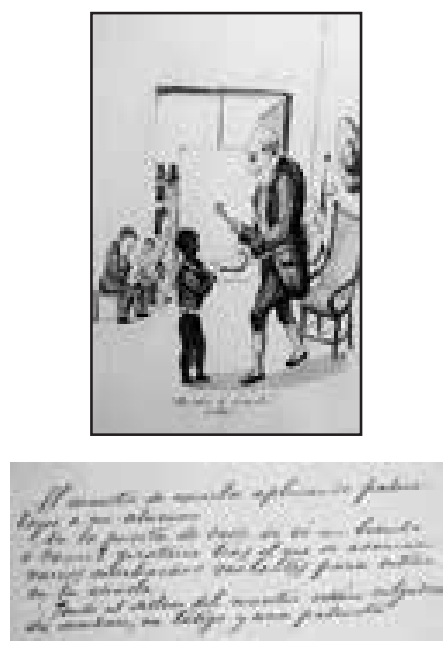

"El maestro de escuela aplicando palmetazos a un alumno. En la puerta de calle se ve un biombo o cancel giratorio tras el cual se asoman varios muchachos vacilantes para entrar en la escuela. Junto al sillón del maestro están colgados su sombrero, un látigo y una palmeta".
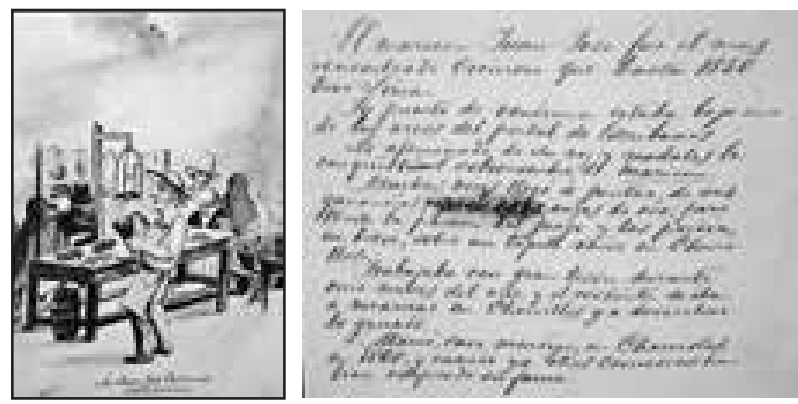

“El maricón Juan José fue el más renombrado cocinero que hasta 1850 tuvo Lima. Su puesto de vendimia estaba bajo uno de los arcos del portal de Escribanos. Lo afeminado de su voz y modales le conquistaron el sobrenombre de maricón. Muchas 
veces llegó a juntar, de sus ganancias, quinientas onzas de oro, pero tenia la pasión del juego y lo perdía, en breve, sobre un tapete verde en Chorrillos. Trabajaba con gran tesón durante once meses del año, y el restante se iba a veranear en Chorrillos y a derrochar lo ganado. Murió casi mendigo, en Chorrillos, en 1860 y cuando ya otros cocineros habían eclipsado su fama”.
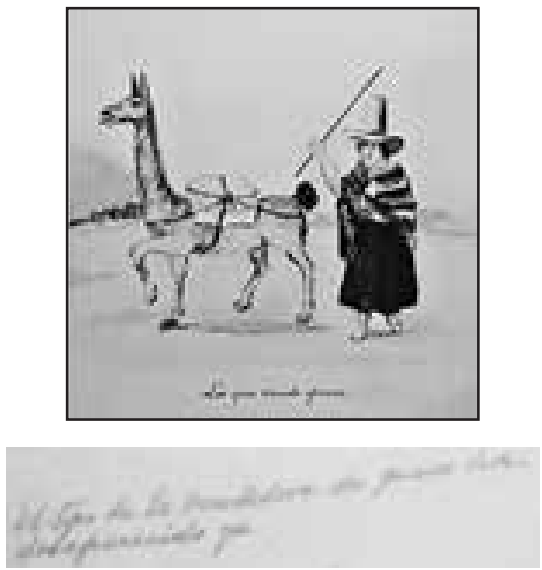

El tipo de la vendedora de queso, ha desaparecido ya.

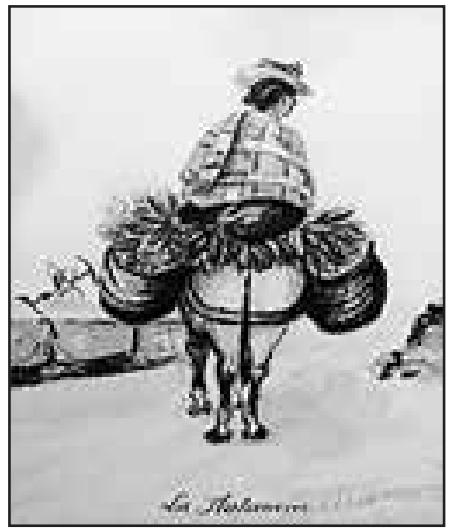

La platanera 

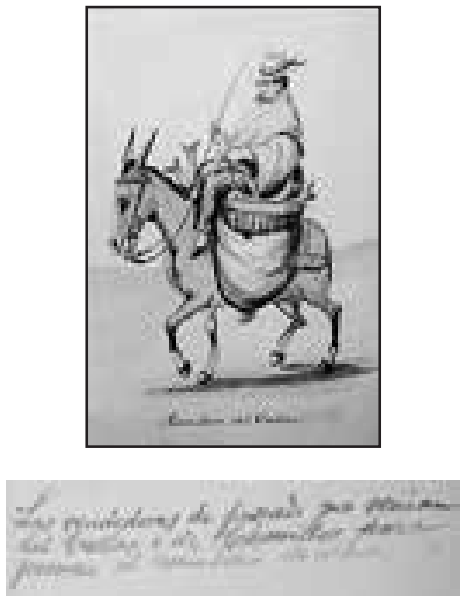

"Las vendedoras de pescado que venían del Callao o de Chorrillos para proveer al vecindario de Lima".

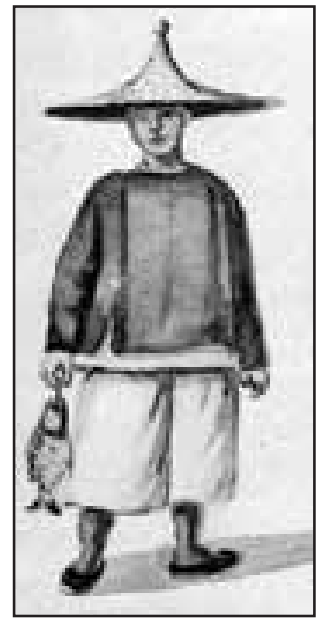

Colie chino, vendedor de pescados. Probablemente también de comidas en las fondas concurridas por la población marginal de Lima del 800. 


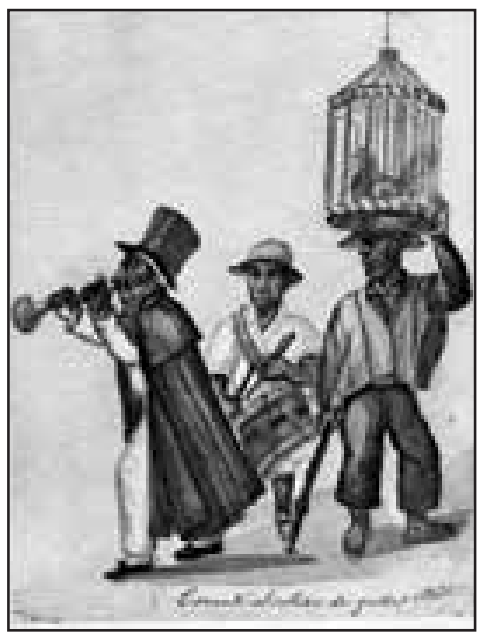

Convite al Coliseo de gallos (1830). Esta costumbre duró hasta 1842 tal como está representado en la acuarela. También hay otra acuarela referida al convite para la comedia, en la que Ricardo Palma anotó: "algunos muchachos vestidos con trajes idénticos a los de los cómicos y precedido de caja y chirimía (flauta de sonido agudo), iban llevando un cartel en que estaba pintado la principal escena de la obra que debía representarse en la noche. Esta mojiganga duró hasta 1840".
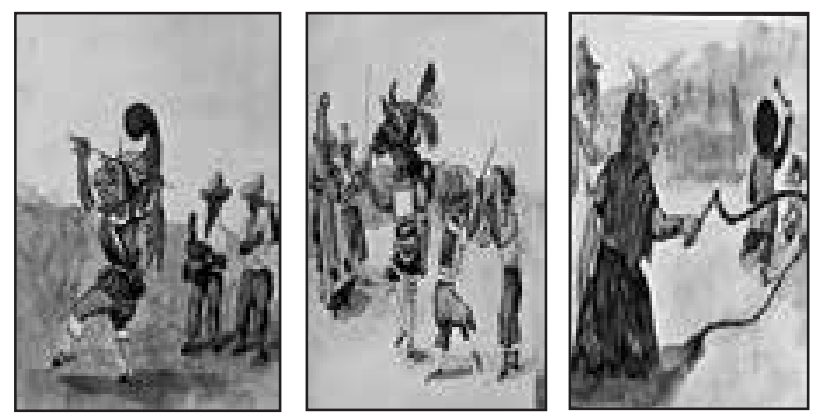

Al son de los diablos 
Esta era una de las danzas principales en Cuasimodo y aun en otras fiestas públicas. Salían casi siempre con los Gigantes. Eran tres parejas. Matrimonio de gigantes indios, matrimonio de gigantes negros y matrimonio de gigantes españoles. Estos tenían una hija llamada Gigantilla, la cual declamaba delante del Santísimo una loa que empieza así: Padre no me diréis vos aquello blanco qué sea, que a mí me parece oblea y el cura dice que es Dios? El hombre que iba dentro de los gigantes de cartón asomaba la cabeza por la barriga de estos. De aquí viene el refrán: hablar como el gigante, por la bragueta.
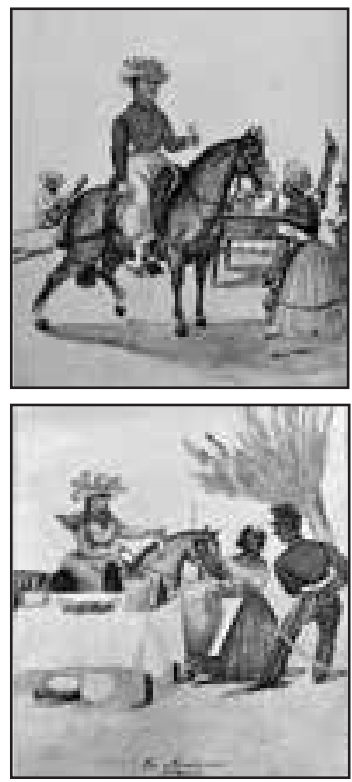

Amancaes se hallaba en las afueras de Lima y se caracterizaba por su clima seco y sus áreas verdes y floreadas especialmente en los "veranillos de San Juan", en el mes de junio. Como parte de los homenajes a San Juan Bautista se decían misas y se presentaban espectáculos musicales y danzas alusivas amén de buen beber y de las pachamancas pantagruélicas. (W.K.) 


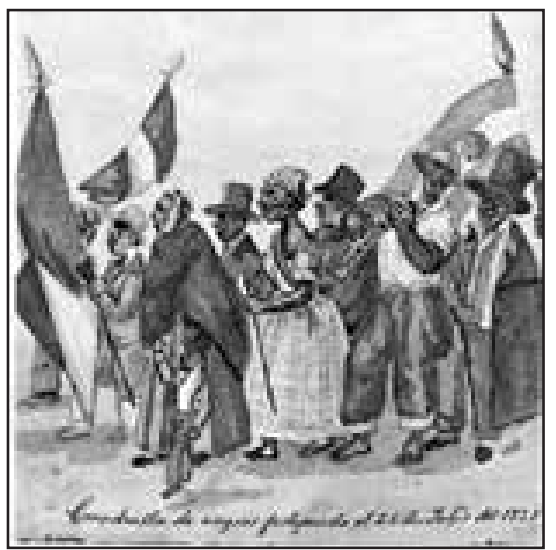

Cuadrilla de negros festejando el 28 de julio de 1821.

Esta acuarela representa irónicamente la alegría de los libertos (mozambiques, angolas, caravelís, chal y terranovas), festejando y dando vivas a la Independencia Peruana, proceso en el cual lucharon indistintamente enrolándose en los ejércitos libertadores de Don José de San Martín y de Simón Bolívar. La Ley de Vientres (declarando que los hijos de los esclavos nacidos después del 28 de Julio de 1821 , serían libres) nunca se llevó a la práctica, pues pocos años después se dispuso que ellos debían permanecer hasta los 50 años al interior de los galpones de las haciendas en la misma condición de negros esclavos. (W.K.).
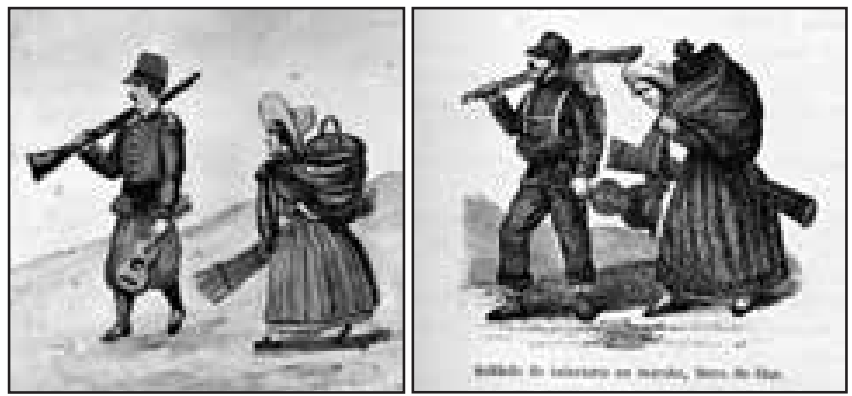

El soldado y su rabona. 
Las mujeres participaron activamente en las guerras de la independencia, en los enfrentamientos bélicos entre los militares republicanos y durante la Guerra con Chile. Usualmente, su labor era atender logísticamente al soldado por lo cual merecieron el nombre genérico de "Las rabonas". (W.K.).

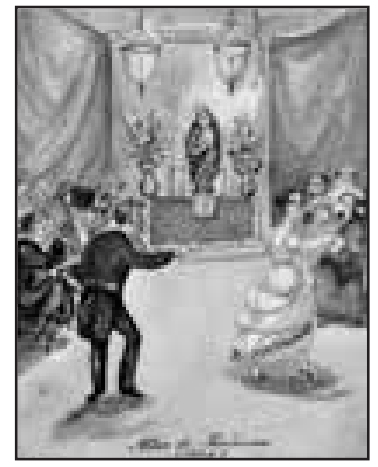

Del 8 al 15 de Diciembre armábase en el salón de las casas aristocráticas un altar en el que ponía una imagen de la Virgen. Eran para la familia 8 noches de sarao (baile). Las señoritas y caballeros bailaban delante del altar el minué y otro baile de buena sociedad. Todavía en 1850 había casas en Lima que no renunciaban a la antigua costumbre del Altar de Purísima, agasajando con helados y pastas a los concurrentes.

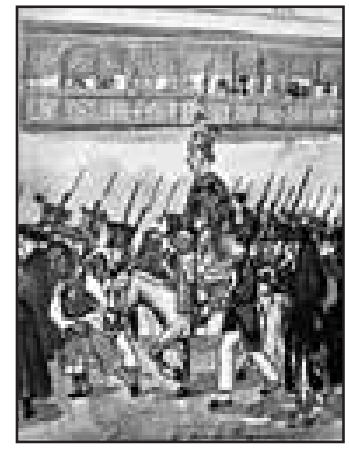




\section{Sentenciado por la Inquisición}

"El penitenciado por la inquisición salía con sambenito y coroza, llevando cadenas en las manos y montado en un burro el cual era tirado por el verdugo. Los balcones de celosía, pintados de verde, existieron en la plaza de Lima hasta 1854, poco más o menos en que los propietarios empezaron a cambiarlos por los actuales."

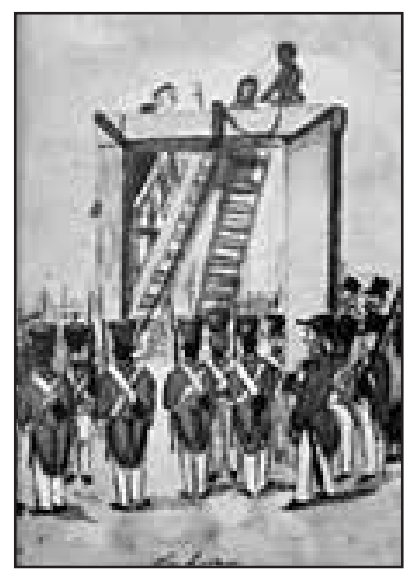

La horca

El cuadro representa al reo con la soga al cuello y en el momento en que el verdugo se prepara a darle la pescozada o empellón. Un dominico acompaña a la víctima. La horca, en Lima, estuvo situada frente al callejón de Petateros, en la Plaza Mayor. Fronteriza al patíbulo había una gran cruz de madera que ahora se encuentra depositada en la Biblioteca Nacional de Lima.

Para más detalles, confróntese el libro de Ricardo Palma Anales de la Santa Inquisición, donde el autor abunda en extenso sobre el problema de la pureza de la fe católica en combate contra las herejías y las blasfemias. 


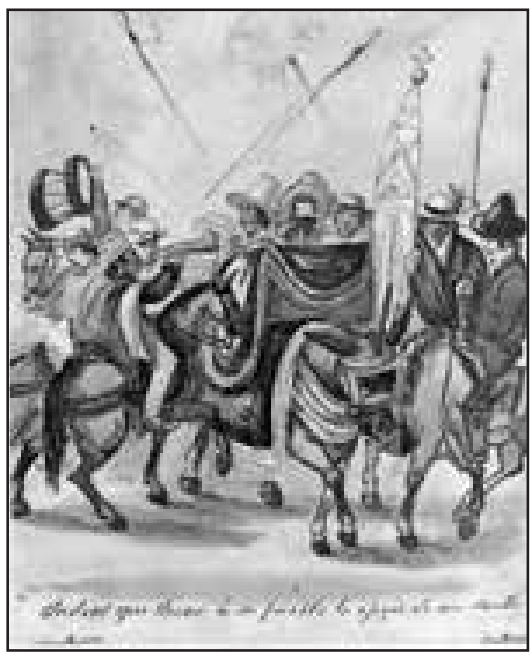

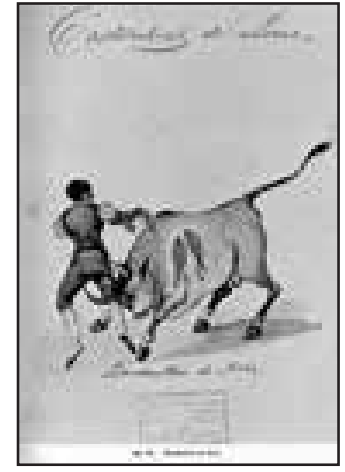

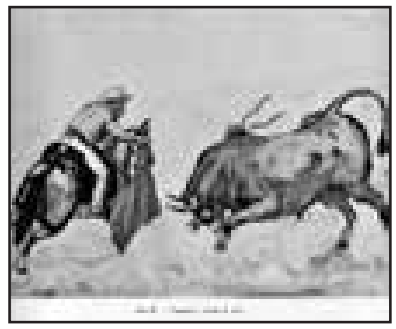

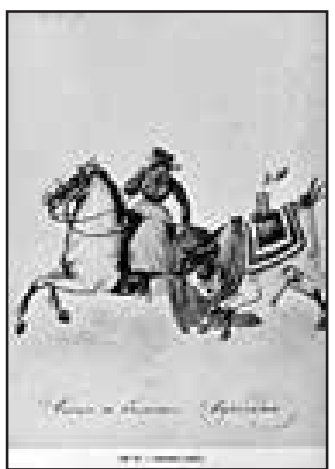

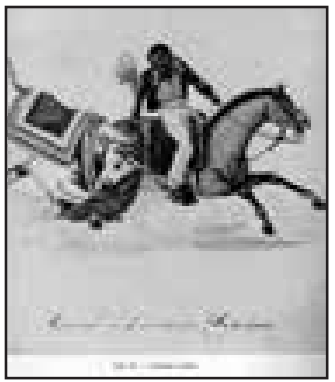


Juanita Breña insigne capeadora, la conocía el pueblo con el apodo de la Marimacho. Véase en mi libro "Tradiciones", la escrita por esta hembra. He aquí el texto al que alude Ricardo Palma.
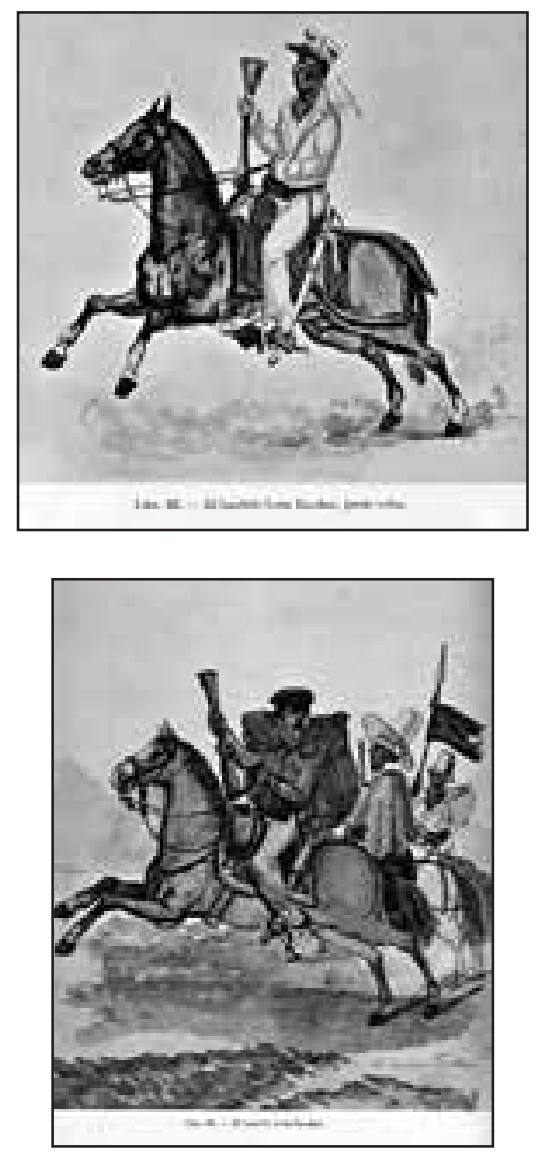

Ricardo Palma tuvo especial consideración al bandolero León Escobar a quien en un fragmento de sus tradiciones lo presenta como "Un Negro en el Sillón Presidencial". A continuación 
transcribimos textualmente la crónica burlesca de nuestro tradicionista.

El 23 de febrero de 1835, a los pocos días de ascendido a general de brigada por el presidente Orbegoso, se sublevó en el Callao don Felipe Santiago Salaverry contra el gobernante constitucional. Tuvo este la debilidad de aspirar a mantenerse en el poder con el auxilio de fuerzas bolivianas, error político que vino a convertir en causa nacional la del faccioso rebelde, simpático joven de veintiocho años, ardoroso y valiente.

Forzado Salaverry a emprender campaña sobre Arequipa, dejó en Lima, con el carácter de prefecto, invistiéndolo con algunas de las facultades inherentes al primer mandatario de la República, al coronel don José Ángel Bujanda, natural del Cuzco.

Para conservar el orden en la capital solo disponía Bujanda de cuarenta soldados de caballería y de poco menos de cien infantes, a quienes estaba encomendado el servicio de policía en la ciudad, amagada por bandas de montoneros capitaneados por algún facineroso, las que mantenían en perpetua alarma al vecindario de los arrabales, haciendo disparos al aire, y al grito de iviva Orbegoso!

Una mañana había salido Bujanda con los cuarenta jinetes a batir una montonera que merodeaba entre Surco y Miraflores, cuando a las doce del día se presentó en Malambo el famoso negro León Escobar, capitán de una cuadrilla de treinta bandidos, los que a todo galope avanzaron desde San Lázaro hasta la puerta de Palacio, en el que la guardia constaba sólo de un teniente, un sargento y seis soldados, que no opusieron la más leve resistencia. Se constituyó León en el salón de Palacio, estacionándose la montonera frente al atrio de la Catedral y vitoreando estruendosamente a Orbegoso. 
El pánico cundió en la ciudad, y todas las puertas se cerraron con llave y cerrojo.

Tres de los ediles, que accidentalmente se encontraban en la Casa Municipal, tuvieron el valor cívico de encaminarse a Palacio para solicitar del jefe de la montonera el que no consintiese que ésta cometiera extorsiones.

El negro Escobar, arrellanado en el sillón presidencial, les brindó asiento en la que fue sala de ceremonia en tiempo de los virreyes, y los trató con toda cortesía, prometiéndoles que no autorizaría el menor desmán, siempre que la municipalidad, de la que aquellos señores investían el carácter de personeros, se aviniese a pagar un cupo de cinco mil pesos en término de dos horas, dinero que necesitaba para atender a las exigencias y manutención de su gente. La conferencia o discusión duró poco más de media hora, aviniéndose al fin los concejales a pagar sólo la mitad del cupo antes de las tres de la tarde, compromiso que se apresuraron a cumplir.

Conocí y traté, allá en mi mocedad, a uno de los ediles, quien me aseguraba que el retinto negro, en el sillón presidencial, se había comportado con igual o mayor cultura que los presidentes de piel blanca.

Poco después de las tres de la tarde, y dando entusiastas vivas a su caudillo, abandonó la montonera nuestra capital, siguiendo la misma ruta de su entrada.

Bujanda, como los carabineros de la opereta, llegó trop tard de regreso de su excursión por Chorrillos y Miraflores, excursión en la que no quemó pólvora. 


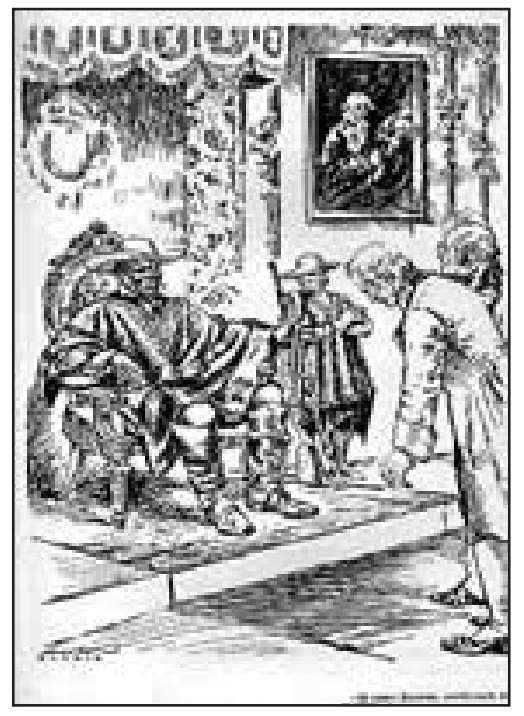

\section{Bibliografía}

ANGRAND, Leonce. Imagen del Perú en el siglo XIX. Lima, ed. Milla Batres, 1972.

CISNEROS SANCHEZ, Manuel. Lima del 800. Madrid, ed. Seix Barral. 1956.

CUNEO HARRISON, Luis. La Virgen del Rosario de Tacna, Mariscala de las Armas de Castilla. Lima, folleto de 1960

KAPSOLI, Wilfredo. La Esclavitud en el Perú. En: Tradición N 14, revista del Rectorado de la Universidad Ricardo Palma. En proceso de edición.

PALMA, Angélica. Pancho Fierro, un acuarelista limeño. Lima, ed. Codex, 1938.

PALMA, Ricardo. Las Tradiciones Peruanas. Lima, ed. Océano. 1962. 
PORRAS BARRENECHEA, Raúl. Palma la Tradición y el Tiempo. Lima, ed. URP 2008.

PORRAS BARRENECHEA, Raúl. Estudios Garcilasistas. Lima, ed. Universidad Garcilaso de la Vega 2009.

RUGENDAS, Juan Mauricio. El Perú Romántico del siglo XIX. Lima, ed. Milla Batres, 1975.

SABOGAL, José. "La obra del pintor Pancho Fierro". EN: Arte y Biografía. Ed. Municipalidad de Lima, 1959.

SHADEL, Richard. “Acuarelas de Martínez Compañón”. En: Lista del Museo Nacional de Historia. Lima, Tomo XXII. 1953. 